\title{
Proceeding
}

Supplementary Issue: Summer Conferences of Sports Science. First International Conference in Iraq on Sport for Peace, 4 April 2019. Baghdad Science Institute, Baghdad, Iraq.

\section{Pedagogical management of the quality of training for a physical culture specialist in higher school: An expectation approach to the problem}

\author{
SERGEY G. EZHOV ${ }^{1}$, IRINA D. LEVINA², OLGA V. MIZONOVA ${ }^{3}$, LYUBOV I. UKOLOVA ${ }^{4}$, MARIA A. KUZNETSOVA ${ }^{5}$, \\ NATALIA G. ENIASHINA ${ }^{6}$, LYUDMILA A. BEZBORODOVA7 \\ ${ }^{1}$ Department of Physical Culture, Ural Federal University named after the First President of Russia B.N. Yeltsin, \\ Yekaterinburg, Russia \\ 2Institute of Culture and Arts, Moscow City University, Moscow, Russia \\ ${ }^{3}$ Department of Psychology, Ogarev Mordovia State University, Saransk, Russia \\ ${ }^{4}$ Department of Music Art, Moscow City University, Moscow, Russia, Russia \\ ${ }^{5}$ Department of Human Anatomy, the Sechenov First Moscow State Medical University, Moscow, Russia \\ ${ }^{6}$ Department of Psychology and Pedagogy, Ulyanovsk State University, Ulyanovsk, Ulyanovsk, Russia \\ ${ }^{7}$ Department of the Theory and Practice of Primary Education, Moscow Pedagogical State University, Moscow, Russia
}

\begin{abstract}
The paper is devoted to the problem of pedagogical management of the quality of training for physical education specialists in higher education: the authors have determined theoretical and methodological foundations of the problem, a conceptual model and pedagogical conditions for its implementation have been presented. The authors of the paper have proved that professional expectations are a construct that anticipates actions aimed at building professional competence, but at the same time it is a product of the processes of mastering the education content. The expectation approach suggests considering the pedagogical management of the quality of training for specialists in physical education at a pedagogical university as a process of changing and shaping professional expectations of the subject of the educational process. In our study, the expectation approach is based on the conceptual ideas of the axiological, competence, and integrative constituent elements. The identified axiological, competence, and integrative constituent elements of the expectation approach determine the multilevel and hierarchical nature of the theoretical and methodological fundamentals of pedagogical management of the quality of training for physical education specialists including the general scientific, concrete scientific, methodological and technological levels of the methodology. Keywords: Expectation approach; Higher vocational education; Management of the quality of training for specialists in physical education; Pedagogical universities.
\end{abstract}

Cite this article as:

Ezhov, S.G., Levina, I.D., Mizonova, O.V., Ukolova, L.I., Kuznetsova, M.A., Eniashina, N.G., \& Bezborodova, L.A. (2019). Pedagogical management of the quality of training for a physical culture specialist in higher school: An expectation approach to the problem. Journal of Human Sport and Exercise, 14(5proc), S2364-S2374. doi:https://doi.org/10.14198/jhse.2019.14.Proc5.51

Corresponding author. Department of Psychology and Pedagogy, Ulyanovsk State University, Ulyanovsk, Ulyanovsk, Russia. E-mail: natalya.enyashina@mail.ru

Supplementary Issue: Summer Conferences of Sports Science. First International Conference in Iraq on Sport for Peace, 4 April 2019. Baghdad Science Institute, Baghdad, Iraq.

JOURNAL OF HUMAN SPORT \& EXERCISE ISSN 1988-5202

(c) Faculty of Education. University of Alicante

doi:10.14198/jhse.2019.14.Proc5.51 


\section{INTRODUCTION}

Development trends of a modern higher educational institution are determined by in-depth educational reforms aimed at raising the quality of higher education. The concept of "quality" embraces all basic functions and activities of the university: the quality of teaching, training and research, the quality of personnel and curricula, the quality of education as a result of teaching and research. The central tendencies to ensure a high level of education lie in an orientation toward students' needs and the creation of optimal conditions for their learning and development. At the same time, an orientation to employer's needs is becoming increasingly important for vocational education. An assessment of the education quality in this case is not of independent interest but is considered as the key to solving urgent practical problems in the country's economy, as well as in each individual educational institution. Therefore, it is required for the Russian system of higher education to update the goals and values of vocational education, it requires innovative approaches to achieve the effectiveness of training specialists based on integrity, openness, flexibility, variability, economic expediency.

The major strategic goal of vocational education is to train a qualified specialist of the appropriate level and profile, competitive in the labour market, competent, responsible, having a perfect command of the profession and knowledgeable about related fields of activity, capable of efficient work at the level of world standards, ready for continuous professional growth, social and professional mobility; meeting the needs of the individual in obtaining appropriate education.

New requirements for the training of specialists in higher education imply going beyond the traditional academic structures with a mono-functional orientation of the educational process and building the educational process of a university that integrates the resource potentials of various socio-pedagogical systems, which makes it possible to update a wide range of opportunities for specialist's professionalization. All this determines the need to develop theoretical, methodological, scientific and practical fundamentals for training a physical education specialist within the educational process of the university, modelling a new type of pedagogical reality and, accordingly, the professional activity of a teacher.

Addressing the quality management problems of contemporary education and their designation as the most important areas of modern scientific knowledge was the result of the increasing importance of quality not only in production processes, but also in education, in society as a whole. The development of scientific research in this direction has revealed the versatility of this phenomenon, which actualized the emergence of various approaches to its analysis. This determined the necessity to realize that the processes of education quality management require a holistic interdisciplinary study, taking into account factors related to both management itself and its sociocultural basis.

The nature of the problem under study determines the use of the scientific principles of the theory of management in sports (Bobreshov, 1990; Bocharov, 1990), the theory of education quality management (Bespalko, 1995; Gershunsky, 1997; Fedorov, 2008), the modern concept of the quality of specialist training (Selezneva, 2001). Issues of education quality management, problems of improving quality based on the latest achievements of pedagogical science are considered in the works of leading teachers and education management specialists V.P. Bespalko (1995), V.I. Zagvyazinsky (2000), N.A. Selezneva (2001), T.I. Shamova (2002). Training of a specialist in the field of physical culture as a system is considered in the works of I. Aronovskaya (2002), N.V. Kuzmina (1993), L.P. Matveyev (1991). The search for ways to organize the educational activities of students, the formation of skills to carry out professional activities and the possibility of developing personal qualities of students in the process of university education are considered in the works 
of V.I. Andreyev (2000), E. Zeer (2005), A.K. Markova (1996), A.M. Novikov (2000), A.A. Galushkin (2015) etc.

The analysis of studies showed that the quality of professional training of specialists in universities should be considered as the ability of the educational system of the university to meet the level of modern educational services, to realize the individual's need for obtaining competitive knowledge and skills. The following is required under these conditions: a mechanism for determining the goals and objectives of training a specialist in physical education, identifying the principles and patterns of development and functioning of a pedagogical university in a new mode, substantiating the organizational, socio-economic and substantive aspects of managing the quality of specialist training, therefore, fundamental research in the field of educational management systems in combination with applied developments are currently relevant and practically significant.

\section{METHODOLOGICAL FRAMEWORK}

The leading trend in the development of modern science - humanization of the educational system - dictates the need to develop new methodological approaches in pedagogy directed to strengthening the subjectsubject relations in the process of pedagogical management. In our opinion, the expectation approach can provide a methodological basis for pedagogical management of the quality of specialist's training in the context of social changes in reality.

The totality of ideas that determine the content of the expectation approach allows us to identify the analysis of concepts that make up the semantic relationships and relations of the concept of "expectation". The concept of "expectation" is considered as a process and as a state. The analysis of the procedural component of expectations is widely represented in psychological research. For instance, A.V. Petrovsky, M.G. Yaroshevsky (1998), considering expectation as a system of expectations. They indicate that the process of social expectation has at least two directions: 1) expectation of others to behave according to their role position; 2) the obligation to behave in accordance with the expectations of other people.

Expectations as a process of presenting the future were considered by F. Polak (2003), who believes that the image of the future reflects the median of expectations of individual social groups, society as a whole in a specific historical and sociocultural situation. Thus, the expectation of the future is associated with a subjective analysis of the present. Designing the "image of the future" involves choosing a life path as a form of man's purposeful organization of his own life, including his attitude to his own capabilities and resources, their actualization and implementation (Polak, 2003).

In social psychology, expectation is a process of representing the future, an attempt to predict the dynamics of an action, or the characteristics of one's personality, and professional expectations fulfil the function of shaping the image of the future that affects a person's behaviour in reality. In socio-psychological theory, considerable attention is paid to the category of social expectations, or "anticipation" which are a system of expectations or requirements regarding the norms for an individual to perform social roles. The system of such expectations fulfils the function of streamlining the system of relations and interaction in the group. In the framework of theories of motivation, a person's professional expectation is formed according to his ideas about the possibilities of satisfying his needs, and professional expectations are regulators of human behaviour. 
The contextual synonymy of the terms "expectation", "forecasting", and "anticipation" also reflects the process of the concept. Contextual synonyms are situational, authorial, individual, and conceptual verbal; they make it possible to make up the lexical deficiency of a concept within the framework of an author's context. Expectations, like forecasting, are directed to anticipating reflection of the future; determination of trends in the dynamics of a particular object or event based on an analysis of its state in the past and present. The strengthening of the "reflection of the future" sign reflects the contextual synonymy of the concepts "expectation" and "anticipation" as a person's ability to more or less predict the development of events, phenomena, and the results of actions.

A.G. Asmolov (1996) considers the problem of probabilistic forecasting in the structure of the subject's activity. The mechanism of possible forecasting acts at the level of operations, which are correlated with the condition for the deployment of actions. Human actions are subordinate in nature, i.e. obey the conscious, expected outcome of actions. When a probabilistic forecasting program is launched in the context of an activity, the subject is guided not only by the possibility of its implementation, but also by its significance for an individual.

The subjectivity and intersubjectivity of expectations as indicators representing the individual's life goal and achievements allow us to explain the formation of expectations and socio-psychological factors that determine expectations in the process of human activity, which are developed in detail in the framework of motivation theories. This approach is applicable to explain the emergence of professional expectations, and also explains their functions in human life.

Expectations as a state are considered in the works of A.V. Tyszkowski. Professional expectations, in accordance with the approach of A.V. Tyszkowski, this is "the mental state of the individual, reflecting the ratio of the subjective assessment of the current situation of interaction and the individual's ideas about himself as a subject of behaviour in this situation" (Tyshkovsky, 1999). Consequently, expectations are a situational category, because they are expressed in readiness to carry out any activity in specific professional (problem) situations. Therefore, expectations as a state are based on a person-conscious meaning, included in subjective experience, having a personal meaning in the system of competencies, which has universal significance, that is, can be used in relation to various types of activities. Expectation is defined as "the internal attitude, the relation or a habit of the mind that leads it to anticipate a specific event," a state that "is perceived by most people as an active anticipation of a future encounter with a tense situation. One of the characteristic features of such a state is the mental reproduction of future activity with the goal of forming its more concrete image" (Tyshkovsky, 1999).

Expectations, being a required component in the structure of social interaction, are transformed from subjective interpersonal into social expectations. For example, A.V. Petrovsky and M.G. Yaroshevsky (1998) apply the term "expectations" in the context of social expectations. Pointing out that "expectations" are "a system of expectations or requirements regarding the norms for the individual to perform social roles; they are a variety of social sanctions that streamline the system of relationships and interactions in a group" the authors identify prescriptive and predictive social expectations. The former has a formal meaning, information about the proper performance of the role. The latter are probabilistic in nature and take into account the individual characteristics of a person and each specific situation. Expectations in this case characterize a person's behaviour, his variability.

Individual and group expectations are highlighted in the context of organizing social interaction. The formation of individual expectations is associated with the assimilation of social roles in the process of socialization. 
Individual expectations reflect a person's ideas about himself, about other people, about the situation. Expectations reflect not only the contemplative activity of a person, but also highlight the ambivalent characteristics of expectations (see table 1).

The modality of expectations indicates the person's features of motivation to achieve. As a rule, with a negative modality of expectations, arises self-doubt, decreases the pace of activity, potential opportunities are not fully realized, unplanned life activity predominates.

Table 1. Types of individual expectations.

\begin{tabular}{|l|l|}
\hline Expectations & Negative \\
\hline Positive & Rigid \\
\hline Flexible & Unrealistic \\
\hline Realistic & Concrete \\
\hline Diffuse & \\
\hline
\end{tabular}

Flexibility-rigidity of expectations indicates the relationship between individual and social expectations. Rigid expectations arise in a situation of complete predictability and forecast, providing stability, reliability of the subject's position in the "environment of their own kind". The flexibility of expectations ensures optimal performance in situations of uncertainty and instability.

Unrealistic-realistic expectations are manifested in the context of building life prospects. Realistic expectations add value to the relationship between the past - present - future with a positive modality of expectations or devalue it with a negative one. A departure from reality, a denial of the past, presupposes the formation of unrealistic expectations that allow one to plan a change in your lifestyle up to its complete opposite.

Concrete expectations are based on the past connection of specific incentives and positive or negative effects and are related to real events. Diffuse expectations arise in a situation of uncertainty, when the connection of stimuli has not formed yet.

Expectations as motivational-cognitive constructs are considered in management theories. For example, in the theory of scientific management proposed by W.F. Taylor (1911), the increase in the labour efficiency of workers was justified, in particular, by their expectations of promotion as a result of a high degree of productivity. In D. McClelland's (1967) theory of acquired needs, expectations are associated with the need for success, power, and involvement. Expectations determine the acceptance of responsibility and relationships with others and the impact on other people.

Motivational stimulation of labour, based on management of expectations, can be traced in the theory of V.N. Vroom (1964). In this case, expectation is the person's assessment of the probability of a certain event in accordance with the expectation of the result, the expectation of reward and the value of the reward. D. Offer et al. (1988) analysing expectations as a premonition of success, introduces the concept of "a play of expectations", which consists in the fact that human activity is determined by the probability of success and self-interest (Offer et al., 1988).

In the context of personnel management, E. Stotland (1969) explores goal achievement. This study is interesting from the point of view of revealing the gradation modality of the level of expectations. Thus, positive expectations above zero in this theory are transformed into hopes, and important goals with a high 
probability of achievement cause positive expectations in the form of joy and optimism. Negative expectations in modality with no hope of achieving a goal, depending on the power of affect, turn into fears or, at a lower intensity, into worries. Thus, subjective meaning fulfilment of expectations is presented in E. Stotland's (1969) theory.

Expectations in domestic psychology are considered in the framework of psychology of labour. Expectations in the context of professional expectations are described in the works of L.I. Bozhovich (1955), E.F. Zeer (2005), A.K. Markova (1996) et al. Professional expectations, in the plane of professional self-determination, are an integral part of professional self-determination and perform the function of factors that determine a person's ideas about personally significant results of professional activity.

\section{RESULTS AND DISCUSSION}

The point of view expressed by T.P. Borisova (2012) is important for our study of expectations from the standpoint of pedagogical management. She explores expectations in the context of the type of social environment of a higher educational institution. According to T.P. Borisova (2012), professional expectations are presented by the predicted changes in social status occurring under the influence of professional activity. Admission to the university, the acquisition of a new social status, becomes in the view of a young man the first step to self-realization of a person, an indicator of social success. In the consciousness of first-year students, a model of the prospective development of personality is created (Borisova, 2012).

Expectations are connected with students' ideas about the future profession, forming the image of the desired future through the context of perception of reality. Self-realization of a person, taking place in the first year of a pedagogical university, is determined by the characteristics of a student entering the world of professional knowledge and relations. However, the formation of a value-meaning attitude to the pedagogical profession, the construction of a meaning field for the development of professional competencies that will be developed, "honed" in subsequent years of study and in subsequent pedagogical activity, building one's own professional self-concept requires activism of a person and, as a result, active self-realization. Therefore, professional expectations become a necessary component in the formation of a professional future of an individual through specific actions in the present (Masalimova et al., 2019; Salakhova et al., 2018; Mitin, 2016).

Professional expectations are filled with value content that gives it meaning. The interaction of subjective meanings and value orientations of pedagogical activity gives rise to the quality of "subjectivity", manifested in personal choice. The insufficient maturity of the regulatory mechanisms of the existential level leads to the fact that a person remains an object of upbringing and external influences, he is limited in his ability to adapt to the environment and therefore the formation of professional expectations becomes a socially determined process. Social expectations become a real component of the pedagogical process, as they are manifested not only in subjective representations, but also in behaviour, being the result of a conscious and unconscious attitude (Salakhova et al., 2016b; Shmeleva et al., 2017).

Thus, we can draw the following conclusions:

1. The content of the expectation approach is made up of semantic relations and relations between the concepts of "expectation", foreseeing the future, "forecasting", and "anticipation".

2. In social psychology, expectation is a process of foreseeing the future, an attempt to predict the dynamics of an action, or the characteristics of one's personality, and professional expectations fulfil the function of shaping the image of the future that has an effect on human behaviour in reality. 
3. Expectations - a situational category that expresses a willingness to carry out any activity in specific professional (problem) situations.

4. Expectations (anticipation) are based on a personally conscious system of competencies, included in subjective experience, having a personal meaning, which has universal significance, that is, can be used in relation to various types of activities.

5. Professional expectations are filled with value content that gives them meaning. The interaction of subjective meanings and value guidelines of pedagogical activity gives rise to the quality of "subjectivity", manifested in a personal choice.

The process of pedagogical management of the quality of training for a specialist in physical education has a number of axiological features that determine the specifics of its technological support: 1) quality management of training for a specialist in physical education is guided by a hierarchy of values that reflects the goal, objectives, content and result of training a specialist in the field of physical education; 2) the main attention is paid to the translation of value orientations in the learning process, which allows us to interpret values as a guideline of activity and behaviour in the process of training a specialist; 3 ) value orientations also influence the quality management of training a specialist in the field of physical culture, since the value and orientation structure of society reflects not only the identity of culture, but also the nature of the transmission of social experience (Babieva et al., 2018; Erofeeva et al., 2019; Goloshumova et al., 2019; Lvova et al., 2018; Salakhova et al., 2016; Mukhametshin et al., 2019).

The competence component of the expectation approach is the theoretical and methodological basis of the study, which allows us to consider the process of pedagogical management of the quality of training for a physical education specialist as a process of activating and supporting professional self-development of students, organizing self-directed educational activities, which implies the active involvement of students themselves in the organization and implementation of this process, delegating of a number of powers to them, separating rights, initiatives, responsibilities between the teacher and students. The purpose of applying the competence-based component of the expositional approach is to recognize as significant the expectations of the educational outcome, to change the units of the educational content and ways of assessing the effectiveness of the educational process (quality assessment) (Oschepkov \& Salakhova, 2016).

The process of training a specialist in physical education and sports must be considered from the standpoint of the integrative nature of human activity. Since physical culture in an integrative aspect represents a holistic process of cultural development, spiritual production, the conscious organization and management of human and social life, in the activity aspect it acts as a combination of intellectual, socio-psychological and motor components, in need-motivational and organizational characteristics. Therefore, the integrative component of the expectation approach is important (Makarova et al., 2019; Kalenik et al., 2018; Shukshina et al., 2015; Grinenko et al, 2019; Salakhova et al., 2015; Kuznetsova et al., 2018; Lekareva et al., 2018; Kalinina et al., 2016; Shumova et al., 2018; Kozyreva et al., 2019).

Integration in training is an organic confluence of the content, methods and forms of organization of the educational process in order to increase its effectiveness, which involves the interaction of the subject and the object in the learning process. The first highest level of integration of training is the level of integrity of intersubject ties, culminating in the formation of a new discipline that is integrative in nature and has its own subject of study. Integrated transitional sciences act as the main source of integration at this level, and, accordingly, the transitional type of integration interaction is the basis of the considered level of integration. The second level of learning integration is the level of didactic synthesis. Didactic synthesis characterizes 
not only the meaningful integration of educational subjects, but also the procedural synthesis that it determines, which primarily involves the integration of forms of educational activities. The third level of learning integration is the level of intersubject ties, which mutually determine the solution of such didactic problems as updating students' knowledge, their generalization and systematization (Salakhova et al., 2016a; Masalimova \& Chibakov, 2016; Shukshina et al., 2017; Sokolovskaya et al., 2019; Salakhova \& Oschepkov, 2017).

The integration of educational subjects at a higher level of systematic content of education should be carried out with the aim to increase motivation to study general educational and special subjects by creating a more real and closer prospect of using the knowledge and skills formed in them, eliminating duplication in the study of a particular educational material, ensuring consistency in the formation of students' knowledge. In this case, the personal components of professional expectations are formed (self-esteem of the person, his attitudes, values, motives, experience of interaction), so professional expectation becomes a combination of personal experience, the experience of other people and the situation.

Thus, the integrative component of the expectation approach is the methodological and technological foundation for the organization of pedagogical management of the quality of training for a physical education specialist, which provides for variability, flexibility, and integration of previously disparate components (theoretical and practical) of training a specialist in the field of physical education in systemic education with certain integral properties and patterns. In accordance with this, the process of integration (integration process) should be considered as a regular, continuous, sequential change of the moments of forming and developing general pedagogical and practical components in the process of training physical education specialists.

\section{CONCLUSION}

Professional expectations are a construct that anticipates actions directed to forming professional competence, but at the same time it is a product of the development of educational content.

The expectation approach suggests considering pedagogical management of the quality of training for a specialist in physical education as a process of changing and shaping the professional expectations of the subject of the educational process.

In our study, the expectation approach is based on the conceptual ideas of the axiological, competence and integrative constituent elements. The identified axiological, competence, and integrative components of the expectation approach determine the multilevel and hierarchical nature of the theoretical and methodological basis in pedagogical management of the quality of training for a specialist in physical education, including the general scientific, concrete scientific, methodological and technological levels of the methodology.

The integrative component of the expectation approach is the methodological and technological basis to organize pedagogical management of the training quality for a specialist in physical education, provides for variability, flexibility, integration of previously separate components (theoretical and practical) of training a specialist in the field of physical education in the system education, which has certain integral properties and patterns 


\section{REFERENCES}

Andreyev, V.I. (2000). Pedagogy. Kazan: Center for Innovative Technologies.

Aronovskaya, I. (2002). Preparation of a specialist as a sociocultural problem. Higher Education in Russia, 4: 115-119.

Asmolov, A.G. (1996). Operation and installation. Cultural-historical psychology and the construction of worlds. Moscow: Voronezh.

Babieva, N.S., Sidyacheva, N.V., Mudrak, S.A., Kalinin, I.V., Zolotkova, E.V., Buyanova, V.V. \& Mikhailova, I.V. (2018). Specific features of self-perception and anxiety of a woman with pathology of pregnancy. Electronic Journal of General Medicine, 15(4): em62. https://doi.org/10.29333/ejgm/93130

Bespalko, V.P. (1995). Pedagogy and advanced learning technologies. Moscow: PRESS.

Bobreshov, V.N. (1990). Management of physical culture and sports movement. Moscow: Vlados.

Bocharov, M.K. (1990). Management Science: A New Approach. Moscow: Press.

Borisova, T.P. (2012). Socio-psychological phenomenology of professional expectations of students in the socio-educational environment of the university: PhD Thesis. Moscow: State University of Management.

Bozhovich, L.I. (1995). Problems of personality formation. Voronezh: Polarees.

Erofeeva, M.A., Grinenko, A.V., Stanovova, L.A., Kosolapova, N.V., Mikhaylovsky, M.N., Rybina, I.A. \& Kochetkov, I.G. (2019). Motivation and motives of juvenile delinquents. EurAsian Journal of BioSciences, 13, 1-6.

Fedorov, V.A. (2008). Pedagogical technologies of vocational education quality management. Moscow: Academy.

Galushkin AA (2015) Education in the field of national information security in the Russian federation and abroad. Journal of Computer Science, 11(10), 988-994. https://doi.org/10.3844/jcssp.2015.988.994

Gershunsky, B.S. (1997). Education in the third millennium: the harmony of knowledge and faith (prognostic hypothesis of educational triumph). Moscow: Moscow Psychological Social Institute.

Goloshumova, G.S., Albakova, ZA-M., Marchev, K.V., Kidinov, A.V., Gustova, E.A., Salakhova, V.B. \& Krasheninnikova, N.A. (2019). The interrelation of environmental and social factors and man's mental health. Ekoloji, 28(107), 6013-6016.

Grinenko, A.V., Gegel, L.A., Poleshchuk, I.A., Tutaeva, D.R., Pronina, E.V., Shchukina, T.V. \& Egorova, E.V. (2019). A governing and political orientation in the field of education. EurAsian Journal of BioSciences, 13, 1-6.

Kalenik, E.N., Salakhova, V.B., Mikhaylovsky, M.N., Zhelezniakova, M.E., Bulgakov, A.V. \& Oshchepkov, A.A. (2018). Psychophysiologic features and personal-adaptive potential of students with limited abilities. Electronic journal of general medicine, 15(6), em98. https://doi.org/10.29333/ejgm/100635

Kalinina, N.V., Kalinin, I.V., Oschepkov, A.A., Salakhova, V.B. \& Simanovskay, M.A. (2016). The Use of Social Resources of Inclusive Educational Environment to Cope Difficult Situations by Adolescents. Mathematics education, 11(7), 2527-2536.

Kozyreva, E.V., Tyurina, N.A., Andreeva, N.A., Merenkova, I.V. \& Kuznetsova, M.A. (2019). Ultrasonic and dopplerometric characteristics of chronic endometritis of women with infertility and miscarriage. Electronic Journal of General Medicine, 16(2), em108. https://doi.org/10.29333/ejgm/106075

Kuzmina, N.V. (1993). Professionalism of pedagogical activity. Rybinsk: RMP.

Kuznetsova, M.A., Klochkova, S.V., Lavrinenko, S.V. \& Nikityuk, D.B. (2018). Nutrition in sports: Present situation and prospects. Teoriya i Praktika Fizicheskoy Kultury, 2, 44-46.

Lekareva, E.E., Zaretskiy, V.V., Artamonova, E.G., Salakhova, V.B., Efimova, O.I. \& Kalinina, N.V. (2018). Comprehensive rehabilitation of minors with deviant and delinquent behavior: The 
experience of the Russian system of education. Eurasian journal of analytical chemistry. Eurasian Journal of Analytical Chemistry, 13(1b), em84. https://doi.org/10.29333/ejac/102249

Lvova, E.N., Khammatova, R.S., Klepach, Y.V., Kazakova, S.N., Shukshina, L.V. \& Dzhafarov, N.K. (2018). Approaches to the study of social situation and its subjective interpretation. Espacios, 39(20), 17-27.

Makarova, E.V., Kryukova, N.I., Sizova, Zh.M., Grinenko, A.V., Erofeeva, M.A. \& Bukalerova, L.A. (2019). Divergence of Supreme Values of Russian World and Western Civilization Social And Philosophical Analysis. European Journal of Science and Theology, 15(3), 97-107.

Markova, A.K. (1996). The Psychology of Professionalism. Moscow: Knowledge.

Masalimova, A.R., Mikhaylovsky, M.N., Grinenko, A.V., Smirnova, M.E., Andryushchenko, L.B., Kochkina, M.A. \& Kochetkov, I.G. (2019). The interrelation between cognitive styles and copying strategies among student youth. Eurasia Journal of Mathematics, Science and Technology Education, 15(4): em1695. https://doi.org/10.29333/ejmste/103565

Masalimova, A.R. \& Chibakov, A.S. (2016). Experimental analytical model of conditions and quality control of vocational training of workers and specialists. Mathematics Education, 11(6), 1796-1808.

Matveyev, L.P. (1991). Theory and methodology of physical education. Moscow: FiS.

McClelland, D. (1967). The Achieving Society. New York: The Free Press.

Mitin, S.N. (2016). Psychotherapeutic approach in the management of the development of educational systems. Simbirsk Scientific Journal Vestnik, 4(26), 31-39.

Mukhametshin, R.Z., Kryukova, N.I., Beloborodova, A.V., Grinenko, A.V. \& Popova, O.V. (2019). Implementation of Efficient Energy Policy in Russia: Energy Consumption Monitoring and Problem Analysis. International Journal of Energy Economics and Policy, 9(4), 224-232. https://doi.org/10.32479/ijeep.7967

Novikov, A.M. (2000). Russian education in a new era. Paradoxes of heritage. Development vectors. Moscow: Egves.

Offer, D., Ostrov, E., Howard, K. \& Atkinson, R. (1988). The teenage world: Adolescents self-image in ten countries. New York: Routledge.

Oschepkov, A.A. \& Salakhova, V.B. (2016). Features of life situations of young people tending to deviant behavior. Simbirsk Scientific Journal Vestnik, 2(24), 37-41.

Petrovsky, A.V. \& Yaroshevsky, M.G. (1998). A Brief Psychological Dictionary. Rostov-on-Don: Fenix.

Polak, F. (2003). The Image of the Future. The world of our tomorrow: Anthology of modern classical forecasting. Moscow: Eksmo Publishing House.

Salakhova, V.B., Belinskaya, D.B., Erofeeva, M.A., Ulyanova, I.V., Zotova, L.E., Khammatova, R.S. \& Mizonova, O.V. (2018). Modern methods of diagnosing addiction to psychoactive substances: neurophysiological aspects. Electronic journal of general medicine, 15(6), 94-106. https://doi.org/10.29333/ejgm/100633

Salakhova, V.B., Bulgakov, A.V., Sokolovskaya, I.E., Khammatova, R.S. \& Mikhaylovsky, M.N. (2016). Substantive (Content-Related) Characteristics of Deviant Behavior as a Social and Psychological Phenomenon. International journal of environmental \& science education, 11(17), 10609-10622.

Salakhova, V.B., Gnedova, S.B., Emelyanenkova, A.V., Mikhailova, I.V., Sedunova, A.S. \& Enyashina, N.G. (2015). Individual characteristics of students in the course of professional development (as exemplified by the ulyanovsk region of russia). Asian Social Science, 11(3), 168-175. https://doi.org/10.5539/ass.v11n3p168

Salakhova, V.B., Oschepkov, A.A, Lipatova, N.V., Popov, P.V. \& Mkrtumova, I.V. (2016a). Features of Social Attitudes and Value Orientations of Youths and Adolescents Prone to Auto-Aggressive Behavior. International journal of environmental \& science education, 11(16), 9017-9025. 
Salakhova, V.B., Ovsyanik, O.A., Shmeleva, N.B., Lvova, E.N. \& Shabanova, O.V. (2016b). The Problem of Higher Education in the Executive System of Russian Government. International journal of environmental \& science education, 11(4), 9883-9889.

Salakhova, V.B. \& Oschepkov, A.A. (2017). Peculiarities of social groups of teenagers with deviant orientation. Simbirsk Scientific Journal Vestnik, 2(28), 46-54.

Selezneva, N.A. (2001). The quality of higher education as an object of systematic research. Moscow: FIS.

Shamova, T.I. (2002). Management of educational systems. Moscow: VLADOS.

Shmeleva, N.B., Aygumova, Z.I., Carroll, V.V., Babieva, N.S. \& Gasanova, P.G. (2017). Creativity in the Teenager's personality structure. Man in India, 97(9), 143-150.

Shukshina, L., Mizonova, O., Katainen, V. (2017). The integration of the educational space in secondary schools and universities as a pre-requisite for the formation of historical thinking. Integration of Education, 21, 86-95. https://doi.org/10.15507/1991-9468.086.021.201701.086-095

Shukshina, L., Mizonova, O., Motchalov, E. \& Eldin, M. (2015). The Mechanisms of Social Illusions and Their Development. Review of European Studies, 7, 10-24. https://doi.org/10.5539/res.v7n6p282

Shumova, N.S., Babieva, N.S. \& Baykovskiy, Y.V. (2018). Self-rating capacity building in female volleyball players. Teoriya i Praktika Fizicheskoy Kultury, 11, 14-16.

Sokolovskaya, I.E., Grinenko, A.V., Miroshkin, D.V., Udodov, A.G., Egorova, E.V. \& Diatlova, E.V. (2019). The Eco-Psychological Approach in the Psychological Follow-Up Program for Children with Limited Abilities. Ekoloji, 107, 659-664.

Stotland, E. (1969). The psychology of hope. San Francisco: Joscy-Bass.

Taylor, W.F. (1911). Principles of Scientific Management. New York: Harper \& Row.

Tyshkovsky, A.V. (1999). Socio-psychological foundations of the formation and implementation of expectations in professional choice and career: Doctoral Dissertation. Moscow: State University of Management.

Vroom, V.N. (1964). Work and Motivation. New York: Wiley.

Zagvyazinsky, V.I. (2000). The main contours of the development of Russian education at the beginning of the XXI century and regional educational projects. Education and science: Izv. URO RAO, 2(4), $8-15$.

Zeer, E. (2005). A competency-based approach to the modernization of vocational education. Higher education in Russia, 4, 23-30

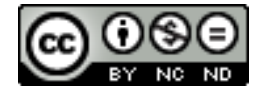

This work is licensed under a Attribution-NonCommercial-NoDerivatives 4.0 International (CC BY-NC-ND 4.0). 